\title{
Determinants of willingness-to-pay a premium for organically produced tomatoes in Riyadh City, Kingdom of Saudi Arabia (KSA)
}

\begin{abstract}
Kamaleldin Ali Bashir
Department of Agricultural Economics, College of Food and Agricultural Science, P. O. Box 2460, King Saud University, Riyadh, Kingdom of Saudi Arabia. E-mail: kbashir@ksu.edu.sa. Tel: +966 1467 8384. Fax: +966 14673557.

Accepted 23 July, 2012

This article analyzes the determinants of consumers' willingness-to-pay premium for organic tomatoes and explores the production potential. Descriptive statistics were used to summarize consumption characteristics and a logit model was used to understand the socioeconomic factors affecting consumers' choices. Results indicated that consumers are willing to pay higher prices for organic vegetables. This willingness varied with four socioeconomic variables: Age, income, education, and wife's employment status and two opinion variables, namely shape and availability of organic products. There is a need to bolster consumers' confidence in organic labels and to inform them about the availability of such products in the market.
\end{abstract}

Key words: Willingness-to-pay, organic vegetables, logit model, market.

\section{INTRODUCTION}

Organic farming ${ }^{1}$ is no longer just an intermittent technique limited to only a few countries. A boom has been witnessed in the last few years in organic farming production that led to wide adoption in almost all countries. Heightened consumers' concerns about real or perceived risks associated with conventional farming, particularly in fresh produce, and consumers' increased awareness about the benefits attributed to organic products may have contributed to fuel interest in such products.

In the Kingdom of Saudi Arabia, KSA, efforts are underway to move towards (or at least encourage) organically produced vegetables. While more efforts and focus have been directed, thus far towards institutional and technical production aspects of organic farming, similar efforts are needed to understand the marketing and consumption aspects. Research endeavours are needed to analyze (potential) consumers' knowledge, attitudes, and perceptions about organic foods. A thorough understanding of the factors which encourage

${ }^{1}$ For definitions and underlying principles of organic farming see IFOAM., FAO (1999). or discourage the consumption of organic products are an equally important research area as well. This research attempts to investigate consumption aspects of organic tomatoes in KSA to complement efforts by local and international organizations to stimulate organic farming in the Kingdom.

The goal of this paper is to analyze and understand aspects of the market for organic vegetables. Specifically, the paper seeks to explore the potential for production; measure the extent of consumers' willingness-to-pay a premium for organic vegetables; identify socioeconomic characteristics that determine such willingness, and hence document a profile of a typical consumer; and to draw some implications to marketing of organic vegetables.

\section{Organic farming in KSA}

Much attention has recently been devoted to organic farming in KSA regarding both the institutional and production levels. The Ministry of Agriculture (MoA) is fostering a program managed by the GTZ, which aims at 
Table 1. Distribution of organic-farming areas by region.

\begin{tabular}{lccc}
\hline \multirow{2}{*}{ Region } & \multicolumn{3}{c}{ Area, HA } \\
\cline { 2 - 4 } & Current (\%) & Underway & Certified (\%) \\
\hline Riyadh & $11948(53.8)^{*}$ & 11818 & $130(1)^{* *}$ \\
Madina & $146(1)$ & 0 & $146(100)$ \\
Qassim & $4939(22.2)$ & 4000 & $939(19)$ \\
Eastern & $124(1)$ & 86 & $38(31)$ \\
Aseer & $6(0)$ & 6 & $0(0)$ \\
Hail & $800(3.6)$ & 800 & $0(0)$ \\
Jizan & $7(0)$ & 7 & $0(0)$ \\
Najran & $25(0.1)$ & 25 & $0(0)$ \\
Aljouf & $4220(20)$ & 18 & $4202(99.6)$ \\
Total & $22215(100)$ & 16760 & $5455(24.6)$ \\
\hline
\end{tabular}

Source: Ministry of Agriculture, KSA: guide to organic farming. ${ }^{*}$ Relative to total; ${ }^{* *}$ relative to region.

developing different aspects of the organic sector: capacity building (legislation, certification, monitoring, and quality control) in addition to providing technical aid to potential growers as well as educating consumers (MoA, 2007). While $45 \%$ of arable land in KSA is sandy soils and may apparently exhibit poor ability to sustain organic farming unless treated (Sheta et al., 2007). However, AlOmran et al. (2002) have shown that adding commercially available natural deposits to the soil would alleviate that problem. Therefore, as far as production is concerned, it can be argued that there could be an untapped potential for organic farming in KSA.

Although, the consumption of organic products currently account for a small portion of consumers' food expenditure nevertheless, it represents a market niche with considerable growth potential. A number of factors provide an impetus to the organic movement and even=tually to the expansion of that niche in KSA. Increasing consumers' health awareness and concern about chemical use in conventional vegetables, availability of cheaper labour for the labour-intensive organic production practices, and the rapidly evolving institutional set up are among such factors. Table 1 show that in order of importance, the three regions of Riyadh, Qassim, and Aljouf collectively host $91 \%$ of organic farming areas in KSA while Aljouf and Madina regions lead in terms of certified area. The figures in Table 1 clearly indicate that there is room for improvement. On one hand, the total area of 22215 ha under organic farming still represents a modest $2 \%$ of total arable lands in KSA. On the other hand, in terms of certification, only $25 \%$ of total area is certified.

\section{LITERATURE REVIEW}

It is generally expected that organically produced vegetables are more expensive than their conventional counterpart, mainly due to (the perceived) better quality of products and because of higher production, processing, and distribution costs (Govindasamy et al., 2001a; Organic Farming Research Foundation, 2008; AlRuwis and Nashwan, 2007). Numerous studies have investigated the determinants of consumers' willingness to buy and/or to pay a premium for organic (chemicals free) vegetables and various socioeconomic factors have been cited by these studies. Age, income, and a measure of social class (race) featured as the most important determinant of willingness-to-pay for pesticide-free fresh produce in a study by Misra et al. (1991). Govindasamy et al. (2001b) added gender and frequency of purchasing organic vegetables. Nouhoheflin et al. (2004) found that the most likely factors influencing consumers' willingnessto-pay for chemical free vegetables are the awareness of chemical residue, availability, label, taste, and consumers' professional category acting as a proxy for income level. Income and demographic characteristics of the households are the determinants of consumers' willingness-to-pay higher prices for processed foods with organic content (Batte et al., 2004). According to Rodríguez et al. (2008), while prices are important determinants, yet consumers are willing to pay a premium for organic vegetable; however, lack of store availability, inadequacy of a reliable regulatory system, lack of information available to consumers, and irregular supply are among the factors that curb the growth of domestic demand in Argentina. The current study builds on previous literature to isolate determinants of WTP in the Saudi environment and adds wife's employment status, a proxy for awareness and education.

\section{METHODOLOGY}

\section{Data and variables}

The study utilized primary data collected in May 2008 through a 
carefully designed formal self- administered questionnaire in both Arabic and English. The months of May and June are usually heavy shopping times, as they precede the summer break where most nationals and expatriates usually make travel plans. The questionnaire was handed out to a randomly selected sample of shoppers in four major super markets in Riyadh city: Carrefour, Altamimi, Giant stores (recently Panda), and Hyperpanda. The region of Riyadh houses more than a quarter of the kingdom's population (Ministry of Economy and Planning, 2010) and the capital city Riyadh has over the years been the target for continuous ruralurban migration. In the survey, consumers were quizzed about their willingness-to-pay a premium for a kilogram of organic tomato (as a good representative of vegetables that is consumed almost daily by most households), their perceptions of organic produce quality, their level of awareness of chemical pesticide use in conventional vegetables, and a number of socioeconomic factors presumed most likely to influence their willingness-to-pay a premium for organic vegetables. All survey questions including WTP were in the form of close-ended where consumers would state their preference from a provided list.

A pre-field testing was conducted before the administration of the survey, using a small focus group (14 respondents) to assess the questions content and formatting respondents understanding of general concepts and specific terminology, and to gauge their opinions about the sensitivity or difficulty of the questions. The small group administration of the instrument was then followed by a discussion of their experience, and their feedback was incorporated in the survey.

The final sample included 212 respondents from four major supermarkets in Riyadh. Some of the variables used in the analysis are defined in Table 2 which also presents the means, standard deviations, and frequencies. A quick comparison of the relevant sample characteristics to their population counterparts reveals a reasonable representation. About $69 \%$ of the population was below the age of 35 years, $23 \%$ in the 35 to 54 category, and $8 \%$ in the above 54 years category (Ministry of Economy and Planning, 2010).

\section{Analytical framework: The logit model ${ }^{2}$}

The analytical model used in this study is a discrete choice model. Due to difficulties in the use of standard linear regression techniques for such models, a binary logit model was used in the estimation process: both the attributes of the choice alternatives and the socio-economic characteristics of consumers are used to explain choices. The model is favoured for its asymptotic characteristics and mathematical simplicity. Since the observation unit in this study is the individual consumer, the method of maximum likelihood estimation (MLE) would be the preferred choice (Gujarati, 1992). The model has wide applications in the literature and belongs to a large class of "discrete choice models" that go back to Berkson (1944) and Cox (1970), with subsequent surveys by Amemiya (1981), Maddala (1983) and Maddala (1988). Mathematically, the model can be stated as:

$$
y_{i}^{*}=\beta_{0}+\sum_{j=1}^{k} \beta_{j} x_{i j}+u_{i}
$$

where $y_{i}^{*}$ is commonly known as a "latent" variable which is not observed; what is observed instead is the dummy variable $y_{i}$ such

\footnotetext{
${ }^{2}$ See Cramer (2003) for an extensive review of the model's origins, justification, applications, and estimation issues.
}

that:

$\mathrm{y}_{\mathrm{i}}=1\left\{\begin{array}{l}\text { if } y_{i}^{*}>0 \\ \text { otherwise }\end{array}\right.$

$\left(x_{i j}\right)$ is a set of explanatory variables, $\beta_{i j}$ are coefficients to be estimated, $u_{i}$ is an error term assumed to follow the logistic distribution:

$$
F\left(z_{i}\right)=\frac{\exp \left(z_{i}\right)}{1+\exp \left(z_{i}\right)}
$$

Empirically, the logit model is presented as:

$\log \left(\frac{p_{i}}{1-p_{i}}\right)=\beta_{0}+\sum_{j=1}^{k} \beta_{i j} x_{i j}$

where: $p_{i}=\operatorname{prob}\left(y_{i}=1\right)$, and the left hand side represents the logit or the log of the odds ratio. In this paper, the left hand side, the dependent variable is the consumer's willingness-to-pay a premium for organic tomatoes (WTPOT) and is measured by the dichotomous variable which takes the value of (one) for willingnessto-pay a premium and (zero) for the lack thereof. The explanatory variables include both consumers' characteristics as well as characteristics related to the alternative choices: organic and conventional vegetables. The names and description of variables used to estimate the model, as well as some descriptive statistics of the variables were presented in Table 2 . The set of explanatory variables likely to affect consumers' willingness to purchase organic vegetable were identified following previous studies with the necessary adjustments to suit the Riyadh (Saudi) environment. The final empirical model is presented as:

$\log \left(\frac{p i}{1-p_{i}}\right)=\beta_{0}+\beta_{1}($ wifejob $)+\beta_{2}($ income $)+\beta_{3}($ edu $)+\beta_{4}($ avail $)+\beta_{5}($ age 2$)+\beta_{6}($ shape 3$)$

Variable names are as defined in Table 2. The marginal effects (ME's) which represent the change in probability due to a one unit change in the corresponding independent variable can be calculated using the following formula (Judge et al., 1982):

$$
\begin{aligned}
M E_{j} & =\frac{\partial p\left(y_{i}=1\right)}{\partial x_{i j}}=\frac{\beta_{j_{i}} \cdot \exp \left(-X_{i}{ }^{\prime} \beta\right)}{\left[1+\exp \left(-X_{i}{ }^{\prime} \beta\right)\right]^{2}} \\
& \text { which can aslo be stated as } \\
& =f\left(-X_{i}^{\prime} \beta\right) \cdot \beta_{j}
\end{aligned}
$$

where $f()$ is the probability density function.

\section{RESULTS}

Table 3 shows the variation in premia consumers' are willing to pay for organic tomatoes. About 70 percent of consumers were willing to pay some premium for organic tomatoes while $30 \%$ were unwilling. About $30,33,18,5$, 10 and $5 \%$ of those who are willing to pay, would pay a premium of $1,2,3,4,5$ and 6 riyals, respectively. The majority, about $57 \%$, indicated willingness-to-pay an extra 
Table 2. Variables definitions and selected descriptive statistics $(N=212)$.

\begin{tabular}{|c|c|c|c|c|c|}
\hline Label & Definition & Mean & SD & Frequency & Count \\
\hline $\begin{array}{l}\text { Dependent } \\
\text { WTPOT }\end{array}$ & $\begin{array}{l}\text { Consumers' willingness-to-pay a premium for organic tomatoes } \\
\text { yes }=1 \\
\text { No }=0\end{array}$ & 0.62 & 0.487 & $\begin{array}{l}61.8 \\
38.2\end{array}$ & $\begin{array}{c}131 \\
81\end{array}$ \\
\hline \multicolumn{6}{|l|}{ Independent } \\
\hline Age & $\begin{array}{l}\text { Age1: if less than } 35=1 \text { else }=0 \\
\text { Age2: if between } 35 \text { and } 54=1 \text { else }=0 \\
\text { Age3: more than } 54 \text { (base group). }\end{array}$ & & & $\begin{array}{c}52.8 \\
38.7 \\
8.5\end{array}$ & $\begin{array}{l}112 \\
82 \\
18\end{array}$ \\
\hline Jobw & $\begin{array}{l}\text { Wife's employment status } \\
\text { Employed }=1 \\
\text { Unemployed }=0\end{array}$ & 0.38 & 0.487 & $\begin{array}{l}38.2 \\
61.8\end{array}$ & $\begin{array}{c}81 \\
131\end{array}$ \\
\hline Edu & $\begin{array}{l}\text { Education of household head, ordinal from } 1 \text { (less than primary) } \\
\text { to } 6 \text { (post university). }\end{array}$ & 4.23 & 1.09 & & \\
\hline Income & $\begin{array}{l}\text { Monthly income in Saudi riyals, ordinal from } 1 \text { (less than 2000) } \\
\text { to } 10 \text { (more than 18000) at increments of } 2000 .\end{array}$ & & & $0.65^{\star}$ & $137^{*}$ \\
\hline \multirow{4}{*}{ CheminV } & $\begin{array}{l}\text { Consumers' perception about presence of chemicals in } \\
\text { conventional vegetables }\end{array}$ & & & & \\
\hline & Yes $=1$ & 0.78 & 0.416 & 77.8 & 165 \\
\hline & $\mathrm{No}=0$ (base group) & & & 22.2 & 47 \\
\hline & If consumers trust labels on organic vegetables & & & & \\
\hline \multirow[t]{3}{*}{ Trust } & Yes $=1$ & 0.65 & 0.479 & 64.6 & 137 \\
\hline & $\mathrm{No}=0$ (base group) & & & 35.4 & 75 \\
\hline & $\begin{array}{l}\text { Consumers' perception on the general appearance (skin) of } \\
\text { organic vs conventional vegetables, dummy with } 3 \text { categories }\end{array}$ & & & & \\
\hline \multirow[t]{4}{*}{ Shape } & Shape1: if worse $=1$ else $=0$ & & & 16.5 & 35 \\
\hline & Shape 3: if better $=1$ else $=0$ & & & 48.6 & 103 \\
\hline & shape 2: same (base group) & & & 34.9 & 74 \\
\hline & $\begin{array}{l}\text { Consumers' perception on taste of organic vs conventional } \\
\text { vegetables, dummy with } 3 \text { categories }\end{array}$ & & & & \\
\hline \multirow[t]{4}{*}{ Taste } & Taste 1: if worse $=1$ else $=0$ & & & 10.4 & 22 \\
\hline & Taste 3 : if better $=1$ else $=0$ & & & 52.8 & 112 \\
\hline & Taste 2: same (base group). & & & 36.8 & 78 \\
\hline & $\begin{array}{l}\text { Consumers' perception on whether chemical residues in } \\
\text { conventional vegetables are risky }\end{array}$ & & & & \\
\hline \multirow{3}{*}{ Residue } & Yes $=1$ & 0.58 & 0.495 & 57.5 & 122 \\
\hline & No $=0$ (base group) & & & 42.5 & 90 \\
\hline & Availability of organic vegetables & & & & \\
\hline \multirow[t]{2}{*}{ Avail } & Yes $=1$ & 0.53 & 0.5 & 52.8 & 112 \\
\hline & No $=0$ (base group) & & & 47.2 & 100 \\
\hline \multirow[t]{3}{*}{ EnvH } & $\begin{array}{l}\text { If consumers believe use of chemicals is harmful to the } \\
\text { environment }\end{array}$ & & & & \\
\hline & Yes $=1$ & 0.87 & 0.339 & 86.8 & 184 \\
\hline & No $=0$ (base group) & & & 13.2 & 28 \\
\hline EnvP & If consuming organic vegetables helps protecting the & & & & \\
\hline
\end{tabular}


Table 2. Contd.

environment
Yes $=1$
No $=0$ (base group)

* Figures are for respondents whose income is in the 4000 to 10000 range.

Table 3. The distribution of willingness-to-pay by premium (SR per kg).

\begin{tabular}{cccc}
\hline Premium (SR/kg) & Frequency & Percent & Cumulative percent \\
\hline 0 & 63 & 29.7 & 29.7 \\
1 & 44 & 20.8 & 50.5 \\
2 & 49 & 23.1 & 73.6 \\
3 & 27 & 12.7 & 86.3 \\
4 & 7 & 3.3 & 89.6 \\
5 & 14 & 6.6 & 96.2 \\
6 & 8 & 3.8 & 100.0 \\
\hline
\end{tabular}

Mean $=1.74 ; \mathrm{SD}=1.67$

1 to 3 riyals per one kilogram of tomatoes. This seems significant, knowing that the price of conventional tomatoes ranges between 3 to 5 riyals throughout most of the year. The mean and standard deviation of the premium consumers are willing to pay were 1.74 and 1.67 riyals, respectively. While these figures indicate a tendency to pay a higher price for organic vegetables, stated preferences may understate the true premium (Florax et al., 2005). The logit model estimation results for the determinants of consumers' willingness-to-pay a premium (WTP) for organic tomatoes are shown in Table 4. The table presents the coefficient estimates ( $\beta$ 's), the marginal effects $\left(M E_{j}{ }^{\prime} s\right)$ which directly give the change in probability due to a one unit change in the relevant explanatory variables, the standard errors, and the attained significance level (p-values) of these estimates. Of the various estimation attempts, this model was chosen, as it captured the most relevant variables determining WTP; while all other models were significant, most variable were either insignificant or had a counterintuitive sign.

Most common statistical packages for example, Eviews, SAS, SPSS, usually report the beta $\beta$ (or the exp $(\beta)$ coefficients which give the effect on (logs of) the odds ratios; both magnitudes are not directly interpretable, that is they do not yield the direct impact on the probabilities. However, the package Limdep 8.0, used for estimation in this study, directly yield these marginal effects as shown in Table 4. These marginal effects are more useful as they lend themselves to a more straightforward interprettation in a similar manner to the usual classical least square coefficients. For explanatory dummy variable, these effects are given as the difference between probabilities $\mathrm{p}(1)$ and $\mathrm{p}(0)$.
In order of importance, the variables: age2, consumers' opinion on the shape of organic products, wife employment status, income, education, availability of organic products, are the most important determinants of consumers' WTP for organic products. All these variables had the expected signs and are significant at conventional levels. The dummy variable "age 2" which corresponds to the (35 to 54 ) years category had the highest impact on WTP: consumers in this age category are likely to pay a premium by a margin of 0.22 relative to the base group (more 54 years). Consumers who thought that the shape of organic is better than conventional vegetables are more likely to pay a premium by a magnitude of 0.16 relative to the base group. In household where the wife is employed, the probability of WTP increases by 0.16 , compared to household with unemployed wives. Likewise, the differential impact of availability of organic vegetables on the probability of WTP is about 0.15: consumers who thought organic vegetables are available are likely to pay a premium by that magnitude. Finally, the results indicate that the variables education and income have incremental marginal effects on the probability of consumers' WTP of 0.063 and 0.048 , respectively along the relevant ranges of these variables.

Table 4 also shows some essential statistics related to model fitness. These include the likelihood ratio statistic, Chi-squared, (44.239) and its p-value (0.00), as well as three different measures of R-squared (Mcfaden (0.16), Effron (0.20), and Veall-Zimmermann (0.30)). The percent of correct predictions $(70.28 \%)$, model sensitivity $(82.44 \%)$, and model specificity $(50.17 \%)$ are other model statistics are displayed in Table 4. 
Table 4. Logit model estimation results for determinants of willingness-to-pay.

\begin{tabular}{lcccc}
\hline Variable & $\boldsymbol{\beta}$ & Marginal effects $\left(\mathrm{ME}_{\mathrm{j}}\right)$ & Standard error & p-value \\
\hline Constant & -2.866 & -0.653 & 0.169 & $0.000^{\star \star \star}$ \\
Wife job & 0.736 & 0.162 & 0.075 & $0.032^{\star *}$ \\
Income & 0.209 & 0.048 & 0.022 & $0.032^{\star *}$ \\
Edu & 0.279 & 0.063 & 0.036 & $0.079^{\star}$ \\
Avail & 0.667 & 0.152 & 0.072 & $0.034^{* \star}$ \\
Age2 & 1.016 & 0.220 & 0.069 & $0.002^{\star * \star}$ \\
Shape3 & 0.728 & 0.164 & 0.072 & $0.024^{\star \star}$ \\
\hline
\end{tabular}

*Significant at 10 percent level. ** Significant at 5 percent level ${ }^{* * *}$ Significant at 1 percent level. Model summary statistics: LR statistics (Chi-squared), 44.239; P-value, $(0.000)^{* \star *}$; Pseudo (McFadden) $R^{2}, 0.157$; Effron $R^{2}$, 0.20; VeallZimmermann R-squared, 0.301; Overall correct prediction (cut off value $=0.50), 70.283 \%$; Sensitivity $(\%$ of $(y=1)$ correctly predicted), $82.443 \%$; Specificity ( $\%$ of $(y=0)$ correctly predicted), $50.167 \%$.

\section{DISCUSSION}

\section{Organic farming potential}

It appears that the prospects for organic products are promising in KSA. On the institutional side, much attention is being accorded to capacity building and technical aid for the benefit of potential growers and to consumer education. On the production side, the figures in Table 1 clearly show an untapped potential. There could arguably be some productivity and efficiency losses accompanying any transition from conventional to organic farming, and hence lower self-sufficiency ratios, more imports, and lower returns in the short run. Such losses may in part be attributable to the no synthetic chemicals requirements and the relatively more labor-intensive nature of organic in respect of conventional production; albeit in KSA cheaper labor is more widely available than in many other countries. As Al-Ruwis and Al-nashwan (2006) noted, for individual farmers, the losses are partially defrayed since organic produce is usually sold at a premium above the price for conventional produce, presumably due to quality improvement. Also, in the long run, the environmental impact of organic farming would help maintain sustainability, and the combining of organic farming with production biotechnologies and soil management techniques may reverse the losses in productivity and efficiency.

On the consumption side, results in Tables 2 and 3 indicate that a substantial untapped market exists for these products on the consumption side: some $62 \%$ of respondents were willing to bid a higher price with some $36 \%$ willing to pay an extra 2 to 3 riyals per one kilogram of organic tomatoes. This probably reflects the consumers' enthusiasm for chemicals free produce and signals their worries about consuming conventional vegetables. Such worries were evident in the descriptive statistics of some of the independent variables in Table 2, where about $78 \%$ of respondents perceived presence of chemical residues in conventional vegetables and $58 \%$ were of the mind that such residues are detrimental to their health.

Consumers heightened concern about the environment lends a further boost to their WTP and hence for the market for organic products, as $87 \%$ believe the use of chemicals is harmful to the environment and $72 \%$ thought that consuming organic vegetables helps protecting the environment. Consumers also seem to have a favourable opinion on some attributes of organic vegetables as $84 \%$ of respondents thought that the shape of organic tomatoes is similar or better and about $90 \%$ thought that the taste of organic tomatoes is similar or better than its conventional counterpart.

There is however some potential marketing hurdles, as some $35 \%$ of consumers do not trust labels on organic vegetables while a significant proportion $(47 \%)$ were of the mind that organic produce is not available on the market. This lack of trust, as well as production and market information could represent a crucial limiting factor for growth and improvement of organic farming (OFRF, 2008). In this regard, Antle (1999) has pointed to the problem of imperfect information for consumers, producers, government regulators, and researchers about the quality attributes of food products, that is safety attributes, convenience, place and manner of production, and environmental concern. Such caveats are particularly important for organic produce, given the many claims being promoted about these products. Marketers of such products need to pay attention to these hurdles by building consumers' confidence through establishing and maintaining independent certification regimes and through promotional campaigns about presence of organic produce.

\section{Determinants of WTP}

The overall model provides a good fit for the data. In Table 4, the chi-square statistic rejected the null hypothesis that the explanatory variables as a set were insignificant in explaining variation in the dependent variable at the 0.0001 level of significance. Other model 
fitness statistics indicate its success in capturing the relevant determinants of WTP. The values of the various $\mathrm{R}$-squared measures reported are within the expected range for such models. The percent of overall successful predictions within the sample shown below the model results is also an indicator of goodness-of-fit (Judge et al., 1982); results indicate that the empirical model correctly predicted the state of the dependent variable in $70.28 \%$ of the observations. The model seems to have done a much better job in predicting $(\mathrm{y}=1)$ cases $(82.44 \%)$ relative to $(y=0)$ cases $(50.17 \%)$.

Model estimation showed that four demographic variables, namely age, income, education, and employment status of household mistress and two opinion variables, namely shape and availability of organic products are the most important predictors of the probability of consumers' WTP, a premium for organic tomatoes. In other plausible empirical specifications attempted, other demographic variables including nationality, gender, and job of household head were either insignificant or had an unexpected effect on consumers' bidding behaviour. Likewise, the effects of other opinion variables such as consumers' confidence in labels, taste of organic vegetables, perception on the risk associated with the use of chemicals in conventional vegetables, and concerns about the environment were also insignificant or counterintuitive. These results bode well with other findings in similar studies which generally indicate that consumers of these comparatively higher priced items have traditionally been the more affluent, educated, younger generation who are willing to pay more for organic produce mainly based on the better quality and the absence of pesticide residues (Gifford et al., 2005; Govindasamy et al., 2001a).

\section{Conclusion}

This article uses a logistic regression model and descriptive statistics to measure the extent and determinants of consumers' willingness-to-pay a premium for organic tomatoes and to describe the production potential of organic vegetables in Saudi Arabia. Consumers indicated willingness-to-pay higher prices for organic vegetables. This willingness-to-pay varied with income and demographic characteristics of the households, namely age, education, and wife's employment status in addition to opinion variables regarding availability and quality attributes of organic vegetables. The results provide an encouraging signal for prospective producers of organic produce who might compensate the likely increase in production costs with the premium consumers who are willing to pay for organic produce; they might also benefit from available soil management techniques to compensate for sandy soil's poor ability to sustain organic farming. Eventually, organic farming might gain an appreciable market share, given the conducive institutional framework and the consumers' willingness-to-pay a premium which reflects a good demand potential, given that younger generations are the ones who are giving impetus to this demand. Growers need to build consumers' confidence in the labels on organic vegetables, as the results pointed that such lack of confidence could be a marketing hurdle. Equally important, consumers need to be informed about the presence of organic produce, as the results indicated that a significant proportion believe that organic produce is not available on the market despite its presence, albeit limited, on the major supermarket shelves. The establishment and maintenance of independent certification regimes and the fostering of well designed promotional campaigns could help tackle these potential marketing hurdles. Research institutions could contribute to educational efforts, provided that more attention by governmental institutions such as the ministries of Agriculture and Health is diverted to funding for research and education.

\section{REFERENCES}

Al-Omran AM, Choudhary MI, A.A.Shalaby, and M.M.Mursi (2002). "Impact of Natural Clay Deposits on Water Movement in Calcareous Sandy Soil". Arid Land Res. Manage.16(2):185-194.

Al-Ruwis KN, Al-Nashwan OS (2006). The Effect of Pursuing the Organic Farming of Onion Product on the Saudi Agricultural Economics. J. King Saud Univ, Agric. Sci. (1)19:3-20.

Amemiya T (1981). Qualitative Response Models: A Survey". J. Econ. Literat. 19(4):483-536

Antle J (1999). Benefits and Costs of Food Safety Regulation. Food Policy 24:605-623

Batte M, Beaverson J, Hooker N, Haab T (2004). Customer Willingnessto-pay for Multi-Ingredient, Processed Organic Food Products". Selected Paper prepared for presentation at the American Agricultural Economics Association Annual Meeting, Denver, Colorado, July 1-4. URI: http://purl.umn.edu/20194.

Berkson J (1944). Application of the logistic function to bio-assay. J. Am. Statist. Assoc. 39: 357-65

Cox DR (1970). Analysis of Binary Data. Metheun, London, UK.

Cramer JS (2003). Logit Models from Economics and Other Fields. Cambridge university press, Cambridge, UK.

FAO (1999). Codex Alimentarius Commission Guidelines for the Production, Processing, Labelling and Marketing of organically produced foods". cac/gl 32.

Florax RJ, Travisi CM, Nijkamp P (2005). A meta-analysis of the willingness to pay for reductions in pesticide risk exposure. Eur. Rev. Agric. Econ. 32:441-467.

Gifford K, Bernard J, Toensmeyer U, Bacon R (2005). An Experimental Investigation of Willingness-to-pay for Non-GM and Organic Food Products". Selected Paper prepared for presentation at the American Agricultural Economics Association Annual Meeting, Providence, Rhode Island, July 24-27. URI http://purl.umn.edu/19385

Govindasamy R, DeCongelio M, Italia J, Barbour B, Anderson $\mathrm{K}$ (2001a). Empirically Evaluating Consumer Characteristics and Satisfaction with Organic Products". New Jersey Agricultural Experiment Station, P-02139-1-01. The State University of New Jersey, Rutgers, New Jersey.

Govindasamy R, Italia J, Adelaja A (2001b). Predicting Willingness-toPay a Premium for Integrated Pest Management Produce: A Logistic Approach. Agric. Resou. Econ. Rev. 30:151-159.

Gujarati D (1992). Essentials of Econometrics. McGraw Hill, New York. IFOAM. URL http://www.ifoam.org/about_ifoam/principles/index.html.

Judge G, Hill R, Griffiths W, Lutkepohl H, Lee T (1982). Introduction to the Theory and Practice Econometrics, John Wiley and Sons, New York. 
Maddala GS (1983). Limited-Dependent and Qualitative Variables in Econometrics. Cambridge University Press, Cambridge, MA, USA.

Maddala GS (1988). Introduction to Econometrics. Macmillan Pub. Co. N. Y. USA.

Ministry of Agriculture in association with GTZ (2007). Aldol, Y. and R. Shnin,. (an Arabic translation), O. Hillberg, S. Liegel, G. Raman, F. Lenhof, and R. Glass. A guide to Organic Farming in the Kingdom of Saudi Arabia, Riyadh, KSA.

Misra S, Huang CL, Ott SL (1991). Consumer Willingness-to-pay for Pesticide-Free Fresh Produce". Western J. Agric. Econ. 16:218-227.

Nouhoheflin T, Coulibaly O, Cherry, A, Al-Hassan R, Adegbola P (2004). Consumers' Perceptions and Willingness-to-pay for Organic Vegetable in Benin and Ghana," Inaugural Symposium, African Association of Agricultural Economists (AAAE), Nairobi, Kenya, December 6-8. URI: http://purl.umn.edu/9525

Organic Farming Research Foundation (OFRF) (2008). Info Bulletin No. 16. URL https://ofrf.org/publications/ib/ib16.pdf
Rodríguez E, Lacaze V, Lupín B (2008).Contingent Valuation of Consumers' Willingness-to-Pay for Organic Food in Argentina". 12th Congress of the European Association of Agricultural Economists EAAE. URL: http://purl.umn.edu/43947.

Sheta A, Al-Omran A, Fallata A, Al-harbi A (in Arabic) (2007). "Natural deposits for Organic Farming in Sandy Soils in KSA". Saudi Society for Agricultural Science, Academic Publications Series, \# 12 vol. 7, Riyadh, KSA.

Ministry of economy and planning, central department of statistics \& information (2010). Preliminary Results of General Population \& Housing Census 1431 A.H, Riyadh, KSA,. URL: http://www.cdsi.gov.sa/yb46/Pages/MixFPage.htm 